\title{
Friction and Wear Properties on AZ91D Magnesium Alloy Treated by Anodizing from Phosphate Electrolytic Solution*1
}

\author{
Makoto Hino $^{1}$, Koji Murakami ${ }^{1}$, Atsushi Saijo ${ }^{2}$, Shuji Hikino ${ }^{3, * 2}$ and Teruto Kanadani ${ }^{3}$ \\ ${ }^{1}$ Industrial Technology Research Institute of Okayama Prefecture, Okayama 701-1296, Japan \\ ${ }^{2}$ Hori Metal Finishing Industry Co., LTD., Takahashi 721-8540, Japan \\ ${ }^{3}$ Faculty of Engineering, Okayama University of Science, Okayama 700-0005, Japan
}

\begin{abstract}
The effects of various surface treatments on the friction and wear properties of AZ91D magnesium alloy substrate against the SUJ2 steel ball were evaluated by using a horizontal reciprocating friction and wear test apparatus. The friction and wear properties greatly changed due to the type of surface treatment in spite of being under equal friction and wear testing conditions. Wear loss of AZ91D magnesium alloy anodized from the phosphate solution was greatly reduced in comparison with the other surface treatment such as Dow 17 , conversion coatings and also no surface treatment. The above results suggest that anodizing from the phosphate solution should improve the friction and wear properties of magnesium alloy used for sliding parts. [doi:10.2320/matertrans.L-M2011816]
\end{abstract}

(Received March 30, 2011; Accepted May 25, 2011; Published August 10, 2011)

Keywords: AZ91D magnesium alloy, anodic oxidation, friction and wear property

\section{Introduction}

Recently, there has been a rapid expansion in the use of magnesium alloys, predominantly in the transportation equipment sector, due to the low environmental impact of these materials, for example, their light weight, rich resources, their exceptional recycling characteristics and they are not toxic to the human body, which leads to a good energy efficiency. ${ }^{1)}$ However, magnesium has the lowest electrochemical potential of all the common commercial metals and is extremely prone to corrosion, and therefore requires surface treatment for long-term services. ${ }^{2}$ Currently, the anodizing of magnesium alloys is used as a surface treatment technique to produce a material that has a high resistance to corrosion. Typical currently used treatments, such as Dow $17^{3)}$ and $\mathrm{HAE},{ }^{4)}$ use hexavalent chromium ions or fluorides, which pose environmental problems. From this perspective, an anodizing technique that does not use hexavalent chromium ions and fluorides is desirable.

The authors have already examined another method to protect magnesium alloys by environmental-friendly anodizing $^{5)}$ using an electrolyte consisting of phosphate and ammonium salts without heavy metals and harmful chemical agents such as fluorides, and showed an excellent corrosion protective performance and corrosion mechanism. ${ }^{6)}$ However, there are many aspects of the film characteristics that are not well understood regarding the friction and wear properties.

In the current investigation, an attempt was made to improve the wear resistance of a magnesium alloy by surface treatment such as anodizing from a phosphate solution, or another anodizing by the Dow17 method and phosphating conversion treatment. The effects of various surface treat-

\footnotetext{
${ }^{* 1}$ This Paper was Originally Published in Japanese in J. Japan Inst. Light Metals 60 (2010) 282-287.

${ }^{* 2}$ Graduate Student, Okayama University of Science
}

ments on the friction and wear properties of the AZ91D magnesium alloy substrate were evaluated using a ball-onplate reciprocal friction tester.

\section{Experimental Procedure}

Experiments were conducted using an AZ91D magnesium alloy plate of $3-\mathrm{mm}$ thickness made by die casting. The chemical composition is shown in Table 1. This substrate was polished to a mirror finish by buffing in order to eliminate the effect of the surface roughness. Anodizing was conducted by direct current electrolysis using a solution of phosphate and ammonium salts according to the conditions in described a previous report. $\left.{ }^{6}\right)$ The thickness of the anodized layer was 5 or $10 \mu \mathrm{m}$ which corresponds to the final bias of electrolysis. For comparison, a commercial phosphating conversion treatment (Million Chemicals Co., Ltd., Grander MC-1000) and another anodizing by Dow17 (Thickness: $30 \mu \mathrm{m})$ were also used to prepare the specimens.

SEM observations of the surfaces and cross-sections as well as micro-Vickers hardness tester (Normal load: $49 \mathrm{mN}$, Measurement position: layer center, Number: 10 times) in the cross-sectional direction were carried out on the obtained coatings.

The apparatus used for the friction and wear testing was a ball-on-plate reciprocal friction tester (SHINKO ENGINEERING Co., Ltd., Shuttlebot SSWT). ${ }^{7}$ Friction tests were conducted under the conditions shown in Table 2. Furthermore, the temperature and humidity conditions were strictly controlled, because the atmospheric humidity can influence the test results. ${ }^{8)}$ After the testing, SEM observations of the wear track and measurement of the wear loss using an electron chemical balance (METTLER AT200 Minimum range: $0.1 \mathrm{mg}$ ) were carried out, and the adhesive state was then examined by analysis of the abrasion powder as well as the element mapping in the friction plane by field emission electron probe microanalysis (FE-EPMA). 
Table 1 Chemical composition of AZ91D magnesium alloy. (mass\%)

\begin{tabular}{cccccccc}
\hline $\mathrm{Al}$ & $\mathrm{Mn}$ & $\mathrm{Zn}$ & $\mathrm{Fe}$ & $\mathrm{Si}$ & $\mathrm{Cu}$ & $\mathrm{Ni}$ & $\mathrm{Mg}$ \\
\hline 9.1 & 0.28 & 0.75 & 0.004 & 0.05 & 0.025 & 0.001 & bal. \\
\hline
\end{tabular}

Table 2 Friction and wear testing conditions.

\begin{tabular}{cc}
\hline $\begin{array}{c}\text { Upper spherical specimen } \\
(\phi 10 \mathrm{~mm})\end{array}$ & SUJ2:HV810 \\
\hline Reciprocating slip & $4 \mathrm{~mm}$ \\
\hline Reciprocating frequency & $2 \mathrm{~Hz}$ \\
\hline Normal load & $0.49 \mathrm{~N}$ \\
\hline Cycle number & 7200 \\
\hline Temperature & $295 \pm 1 \mathrm{~K}$ \\
\hline Relative humidity & $60 \pm 1 \%$
\end{tabular}

\section{Results and Discussion}

\subsection{Morphology and hardness of various treated coat- ings}

Figure 1 shows secondary electron images of the surfaces of the untreated and the various treated specimens. The surface of the untreated specimen of the mirror buffing was quite smooth; however, each surface morphology with surface treatment was different. The coating anodized from the phosphate solution had numerous microscopic pores.
During the anodic electrolysis, the sparks that were observed due to the dielectric breakdown led to the formation of these numerous microscopic pores in the coating, and these pores then expanded as the coating thickness increased. During another anodizing method using Dow17, the coatings also had numerous pores, because the sparks were generated during anodic electrolysis, however, the coatings morphology became rougher in comparison to that from the phosphate solution. The coating morphology due to the conversion treatment depending on the electrochemical reaction was smoother than those of the anodizing ones, and numerous peculiar cracks formed by the conversion treatment on the magnesium alloy was observed.

Figure 2 shows secondary electron images of the specimen cross-sections. The coatings anodized in both the phosphate solution and Dow 17 had a porous structure, but there was no pores in the coating obtained using the conversion treatment.

Table 3 shows the Vickers hardness of the substrate and coatings after the various surface treatments. The hardness of the anodized coating from the phosphate solution was $130 \mathrm{HV}$, which was harder than that of the substrate. The hardness of the anodized coating with Dow17 was $250 \mathrm{HV}$, whose value was roughly twice that from the phosphate solution. Concerning the conversion coatings, it was impossible to measure the hardness, because this coating was very thin. The film was partially removed like being rubbed by an eraser. Therefore, it seemed that this coating was not hard.
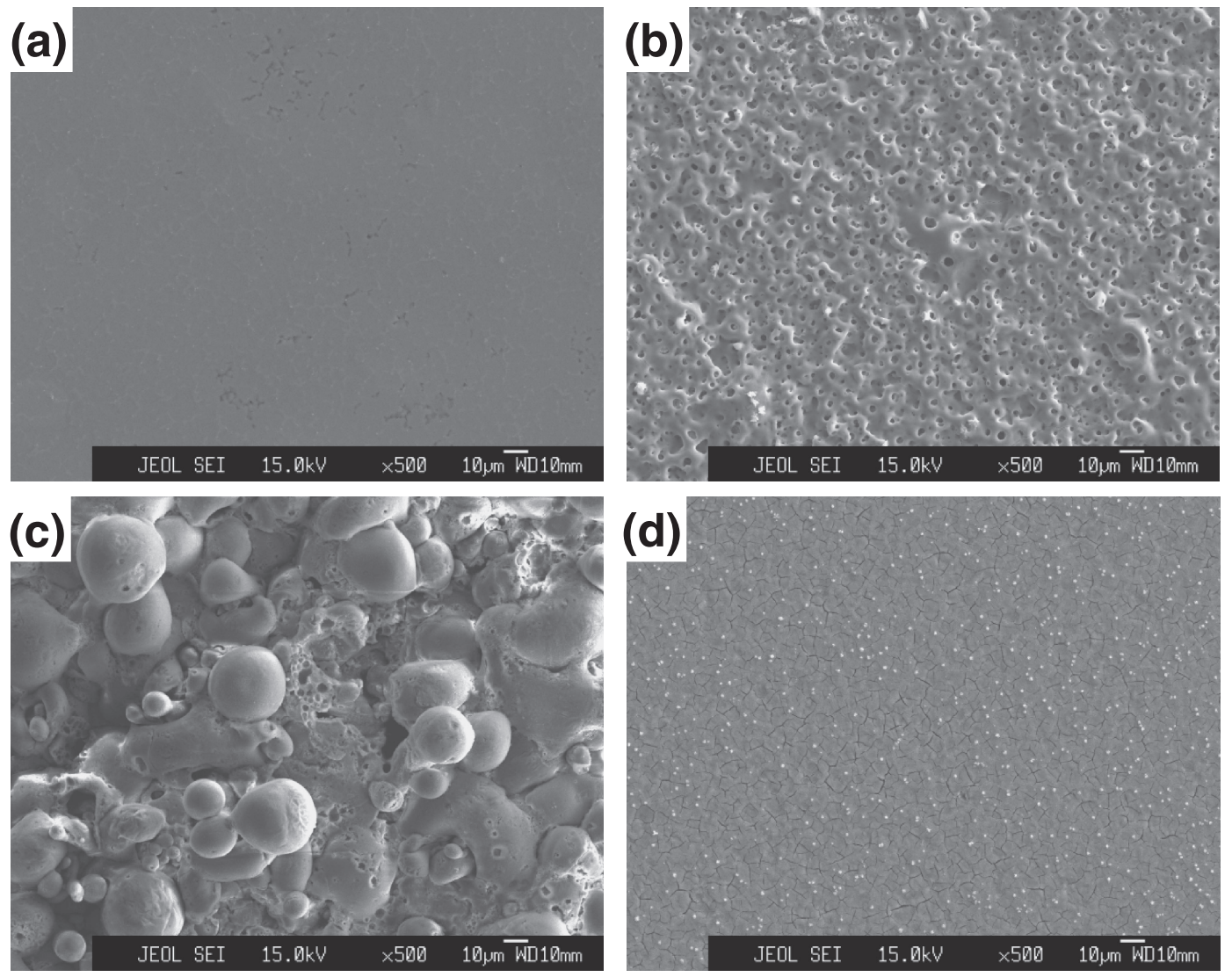

$20 \mu \mathrm{m}$

Fig. 1 Secondary electron images of specimens showing various treated surface on AZ91D magnesium alloy. (a) No treatment (b) Anodizing from the phosphate solution (Film thickness: 10 $\mu \mathrm{m}$ ) (c) Dow17 (d) Conversion treatment. 

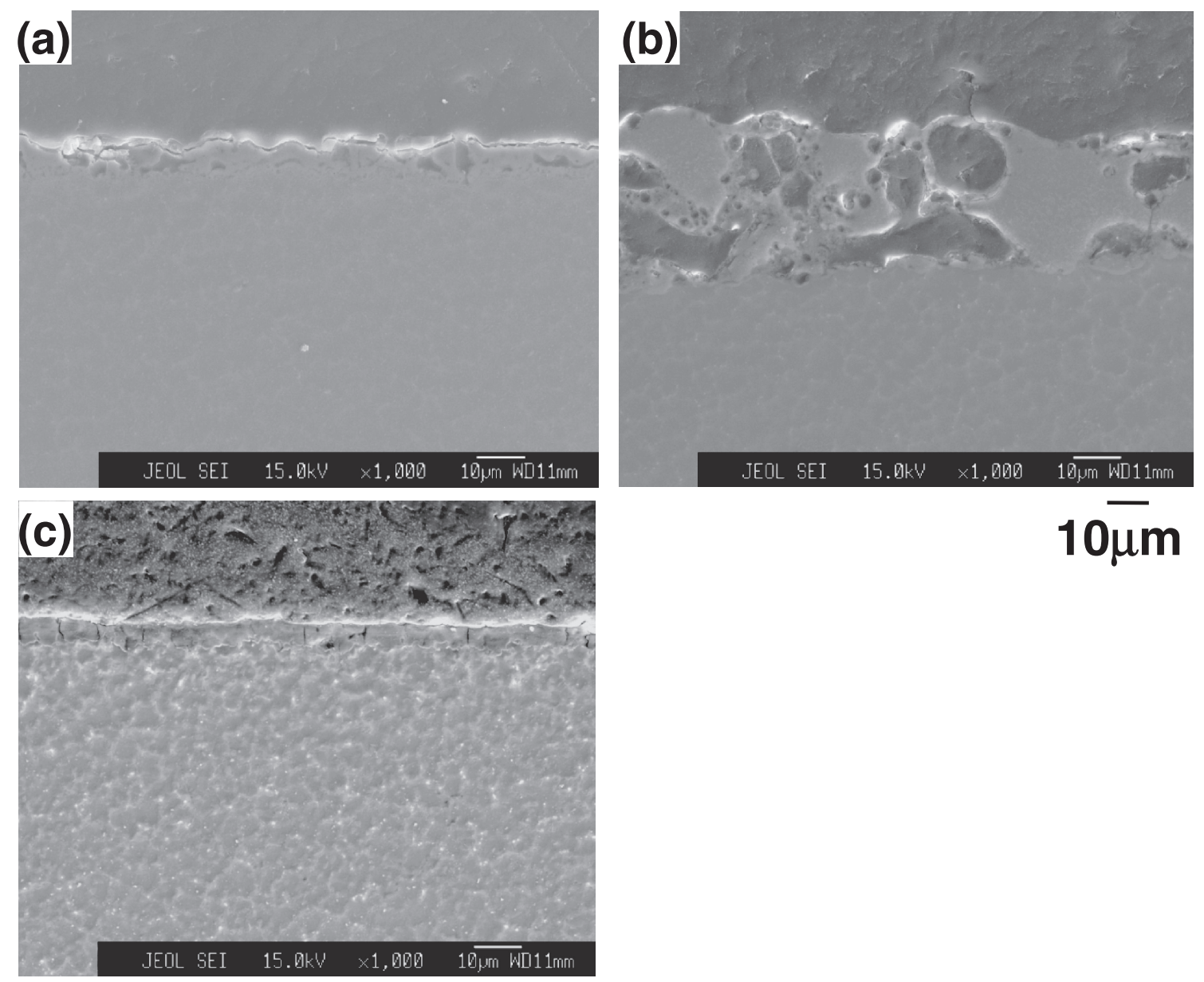

Fig. 2 Cross sectional SEM images of specimens showing various treated surface on AZ91D magnesium alloy. (a) Anodizing from the phosphate solution (Film thickness: $10 \mu \mathrm{m})(\mathrm{b})$ Dow17 (c) Conversion treatment.
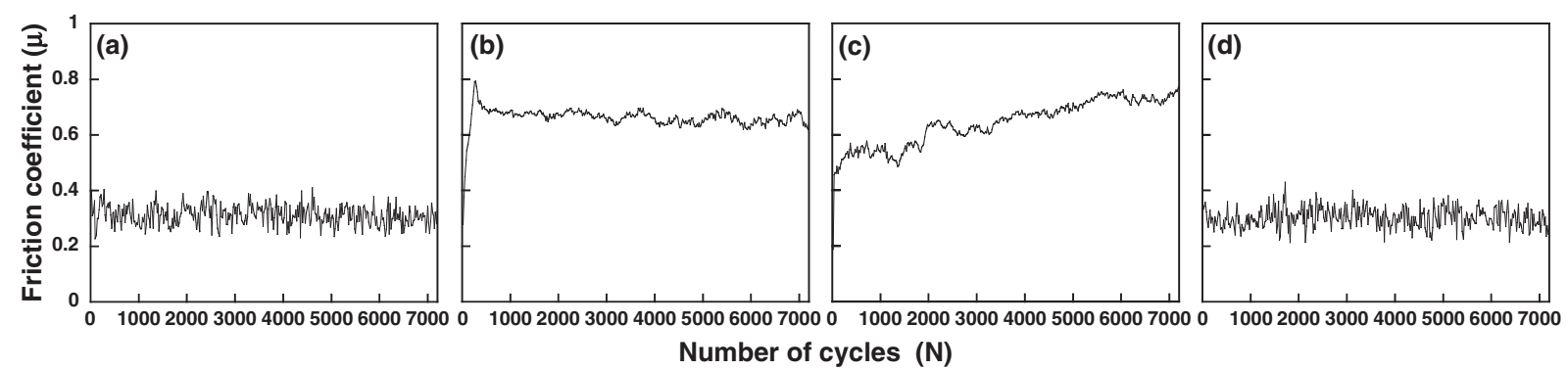

Fig. 3 Variation of the friction coefficients throughout testing. (a) No treatment (b) Anodizing from the phosphate solution (Film thickness: $10 \mu \mathrm{m}$ ) (c) Dow17 (d) Conversion treatment.

Table 3 Hardness of the substrate and coatings with various surface treatments.

\begin{tabular}{ccc}
\hline AZ91D substrate & Dow17 & $\begin{array}{c}\text { Anodizing from the } \\
\text { phosphate solution }\end{array}$ \\
\hline $80 \pm 5 \mathrm{HV}$ & $250 \pm 50 \mathrm{HV}$ & $130 \pm 10 \mathrm{HV}$ \\
\hline
\end{tabular}

\subsection{Friction and wear properties of various surface treated coatings}

The variation in the friction coefficients of the various surface treated coatings throughout the testing are shown in Fig. 3. The friction coefficients after each surface treatment were very different. The friction coefficient of the magnesium substrate without the surface treatment was about 0.3 at the early stage, and then this value was unchanged. The variation in the friction coefficient of the conversion coatings was similar to that of the substrate. As a general rule, the friction coefficient between a metal and another metal should be approximately the range from 0.6 to 1 without lubrication, but the case in which the adhesion between both intensely generated. However, each friction coefficient was about 0.3, therefore, these values are very low.

On the other hand, the friction coefficient of the anodized coating from the phosphate solution was about 0.8 at the early stage, and this value then decreased to about 0.6. 

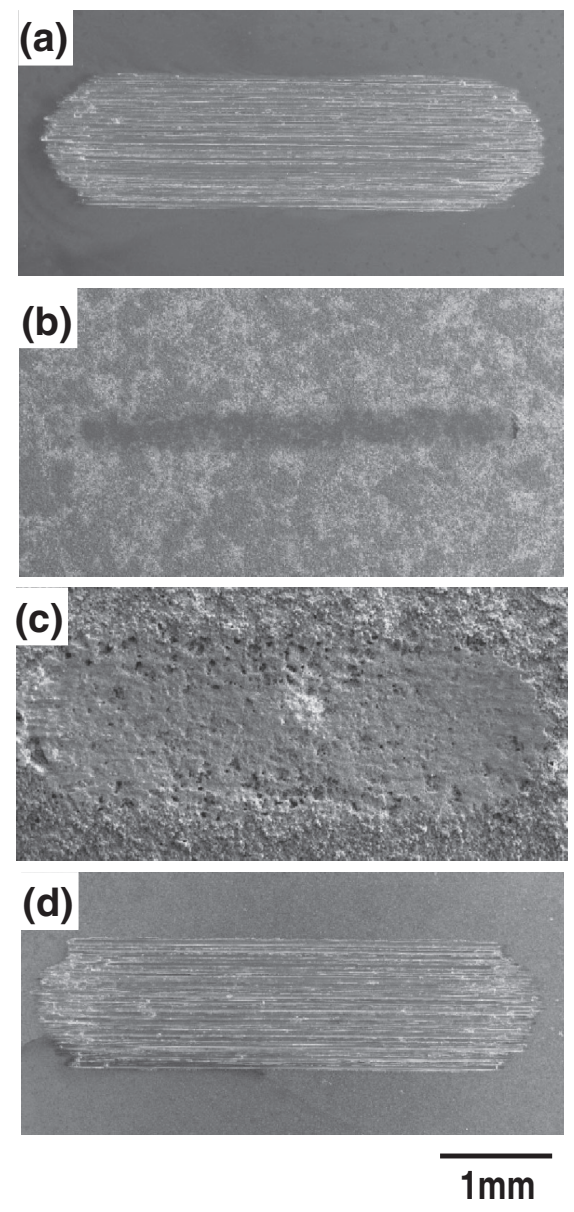

Fig. 4 Appearances of wear track of various coatings slid against SUJ2 ball. (a) No treatment (b) Anodizing from the phosphate solution (Film thickness: $10 \mu \mathrm{m})(\mathrm{c})$ Dow17 (d) Conversion treatment.

Therefore, this value was unchanged. The friction coefficient of the Dow17 anodized coating was about 0.5 at the early stage, and this value then increased with time. Finally, this value became 0.8 .

Figure 4 shows the appearance of wear tracks on the various treated specimens after the friction and wear testing. The untreated specimen was significantly worn against the SUJ2 ball, while the wear of the specimen with the conversion treatment was similar to that of the untreated one. In both of these specimens, each friction coefficient was approximately 0.3 , and this value was low. However, these specimens were drastically worn, as shown in Fig. 4. The decrease in these friction coefficients is attributed to the bearing effect, ${ }^{9)}$ since an abrasion powder was formed in wear surface during the friction and wear testing. Furthermore, during the wire drawing and processing of the steel, it is well known that the phosphate conversion treatment improves the workability by acting as a lubricant. ${ }^{10)}$ However, for the manganese-phosphate conversion treatment of the AZ91 magnesium alloy in this study, there is no lubricating effect similar to that on the steel. This is attributed to the composition of each conversion coating. In addition, the hardness value of each substrate will influence the lubricity. When the friction and wear testing was started, since the magnesium alloy substrate which was not harder
Table 4 Wear loss of the substrate and coatings with various surface treatments.

\begin{tabular}{ccccc}
\hline $\begin{array}{c}\text { AZ91D } \\
\text { substrate }\end{array}$ & $\begin{array}{c}\text { Conversion } \\
\text { treatment }\end{array}$ & Dow17 & $\begin{array}{c}\text { Anodizing from } \\
\text { the phosphate } \\
\text { solution } \\
(5 \mu \mathrm{m})\end{array}$ & $\begin{array}{c}\text { Anodizing from } \\
\text { the phosphate } \\
\text { solution } \\
(10 \mu \mathrm{m})\end{array}$ \\
\hline $0.5 \mathrm{mg}$ & $0.6 \mathrm{mg}$ & $1.5 \mathrm{mg}$ & 0 & 0 \\
\hline
\end{tabular}

than the steel substrate, abraded with a film (Fig. 4(a)), the lubricating effect by a film would be immediately lost.

The Dow17 anodized specimen was also drastically worn; however, the shape of the wear track was different from those of the foregoing specimens. As shown in Fig. 4(c), there was more wear loss at the wear track edge in the central area. For the friction and wear testing equipment used in this study, the sliding speed at the edge of the sliding area is faster than that in the central area, because the rotary motion is converted into a reciprocating motion by the crank mechanism. The results of the foregoing difference in the wear loss of the Dow17 anodized specimen indicated that the sliding speed affects the wear loss.

On the other hand, the wear of the anodized coating from the phosphate solution was remarkably suppressed in comparison to the untreated or the other treated specimens, as shown in Fig. 4(b). Although the Vickers hardness value of the anodized coating from the phosphate solution was approximately one half that of the Dow17 anodized coating, as shown in Table 3, this wear was remarkably suppressed. These results suggest that a factor other than the film hardness exists with regard to the wear property.

Table 4 shows the wear loss of the substrate and coatings after the various surface treatments. The Dow 17 anodized specimen was the most drastically worn in this study, while the wear loss of the untreated specimen was identical to that of the conversion treated specimens. On the other hand, there was no wear loss of the anodized coating from the phosphate solution after the friction and wear testing. Thus, this coating showed an excellent wear resistance, and these results are then in good agreement with the appearances of the wear tracks made by the various surface treatments, as shown in Fig. 4.

Figure 5 shows the appearances of the surfaces of the SUJ2 ball specimens slid against the various coatings. The shape of the ball against the untreated substrate was identical to that of the ball against the conversion coating. From the results of the wear track of each specimen shown in Fig. 4 and the wear loss shown in Table 4, it was found that the conversion coating hardly influenced the friction and wear property of the AZ91 magnesium alloy substrate. The wear track of the SUJ2 ball against the Dow17 anodized coating was the biggest in this study, and the wear debris were found on both sides. A great number of rub scratches along the sliding direction was observed, and it was recognized that the SUJ2 ball was abraded.

On the other hand, the wear track of SUJ2 ball against the anodized coating from the phosphate solution was the smallest in this study. Based on this result and the appearance of the wear track shown in Fig. 4(b), it was found that the 

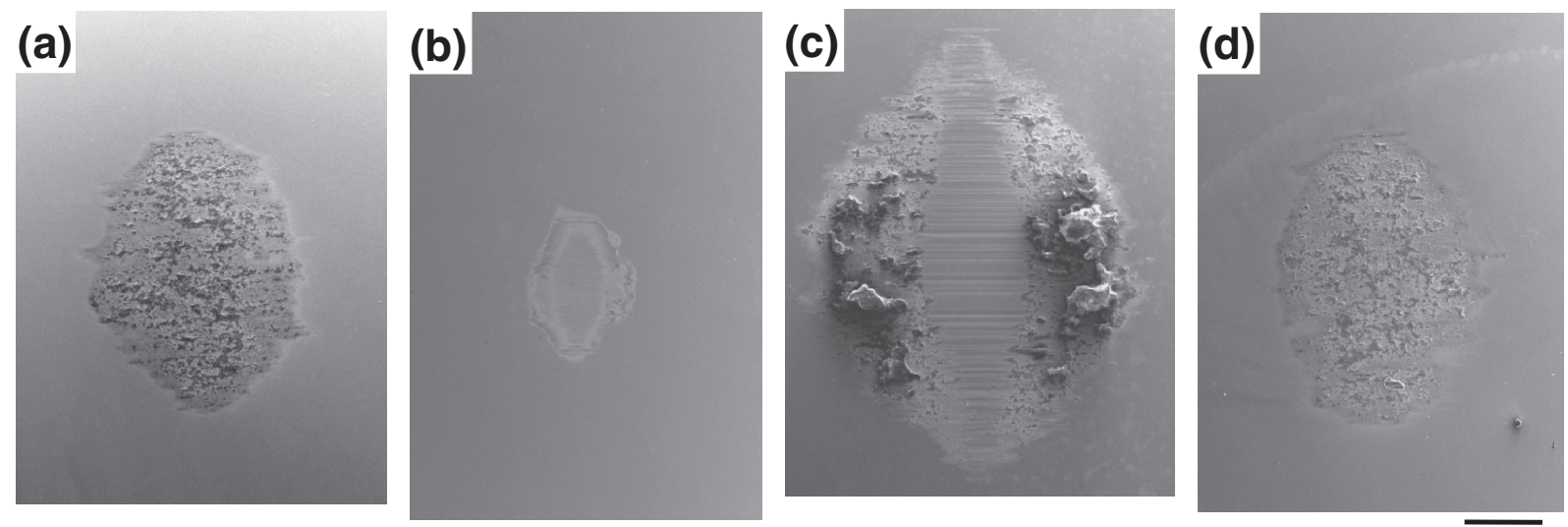

$300 \mu \mathrm{m}$

Fig. 5 Appearances of the surface of SUJ2 ball specimens slid against various coatings. (a) No treatment (b) Anodizing from the phosphate solution (Film thickness: $10 \mu \mathrm{m}$ ) (c) Dow17 (d) Conversion treatment.

Table 5 Chemical composition of wear debris. (mass\%)

\begin{tabular}{|c|c|c|c|c|c|c|c|c|c|c|}
\hline & $\mathrm{Mg}$ & $\mathrm{Al}$ & $\mathrm{O}$ & $\mathrm{P}$ & $\mathrm{F}$ & $\mathrm{Cr}$ & $\mathrm{Na}$ & $\mathrm{Mn}$ & $\mathrm{Ca}$ & $\mathrm{Fe}$ \\
\hline No treatment & 62.2 & 17.4 & 20.4 & - & - & - & - & - & - & - \\
\hline $\begin{array}{l}\text { Anodizing from the } \\
\text { phosphate solution }\end{array}$ & 2.1 & 0.9 & 30.0 & 1.7 & - & 2.0 & - & - & - & 63.3 \\
\hline Dow17 & 19.8 & 1.4 & 17.7 & 8.0 & 26.1 & 18.0 & 6.5 & - & - & 2.5 \\
\hline Conversion treatment & 50.1 & 18.7 & 24.5 & 1.9 & - & - & - & 1.2 & 0.7 & \\
\hline
\end{tabular}

anodized coating from the phosphate solution had an excellent wear resistance.

The chemical compositions of the wear debris, which were created after the friction and wear testing, by the FE-EPMA are shown in Table 5. The wear debris of the untreated specimen consisted of the elements of magnesium, aluminum, and oxygen which were derived from the AZ91D material, and the iron which was derived from the SUJ2 ball was not detected. Those of the specimen with the conversion treatment also consisted in the elements of magnesium, aluminum, and oxygen. In addition, a slight amount of phosphorus, manganese, and calcium, which were derived from the conversion coatings, was detected. Based on these results, it seems that the SUJ2 balls against the untreated specimen and conversion treatment were not abraded.

On the Dow17 anodized specimen, not only the elements, which were derived from the coating, but also the iron, which was derived from the SUJ2 ball, were detected. This result indicates the wear of the SUJ2 ball, and agrees with the appearance of the wear track shown in Fig. 5. In this way, one must be careful for using the Dow17 anodized coating in a sliding position, because not only the coating wore, but also wear the against the material was strong.

On the other hand, the wear debris of the anodized coating from the phosphate solution consisted of the elements of magnesium, aluminum, oxygen, and phosphorus, which were derived from the anodized coating, ${ }^{4)}$ and the iron and chromium, which were derived from the SUJ2 ball. The amount of iron was 63.3 mass $\%$ in the detected elements, and this value was much greater than the other elements. This result indicates that the SUJ2 ball positively abrades compared to the coating. However, the hardness value of the SUJ2 ball was six times that of the coating. Therefore, these results suggest that factors, such as a mechanochemical reaction, ${ }^{11)}$ affect the friction and wear property of both this anodized coating and SUJ2 ball, except for the hardness.

Figure 6 shows the secondary electron images and X-ray maps obtained by the FE-EPMA analysis for the wear tracks of the various coatings and against the SUJ2 ball after the friction and wear testing. On the untreated specimen, magnesium, aluminum, and oxygen were distributed on the worn part of the substrate. The magnesium and aluminum were then derived from the AZ91D magnesium substrate. The distribution of oxygen seems to occur by the oxidation according to the exothermic reaction based on the friction. Also, iron, which was a main component against the ball, was not detected. Next, magnesium and aluminum derived from the AZ91D magnesium substrate and oxygen as well as iron, which is a main component, were distributed on the worn part against the ball. It was proven that the AZ91D magnesium substrate had intensely transferred to the SUJ2 ball due to adhesion. From the results of no iron in the wear debris shown in Table 5 and the evidence of no transfer from the SUJ2 ball to the AZ91D magnesium substrate, the SUJ2 ball seems to only abrade the AZ91D substrate. Besides, the behavior of the specimen with the conversion treatment was also similar to that described above, except for the phosphorus derived from the conversion coating.

On the Dow17 anodized specimen, not only the elements derived from the anodized coating, but also the iron, were distributed on the worn part of the coating, so that the SUJ2 ball was transferred to the coating. Iron, which was a main 


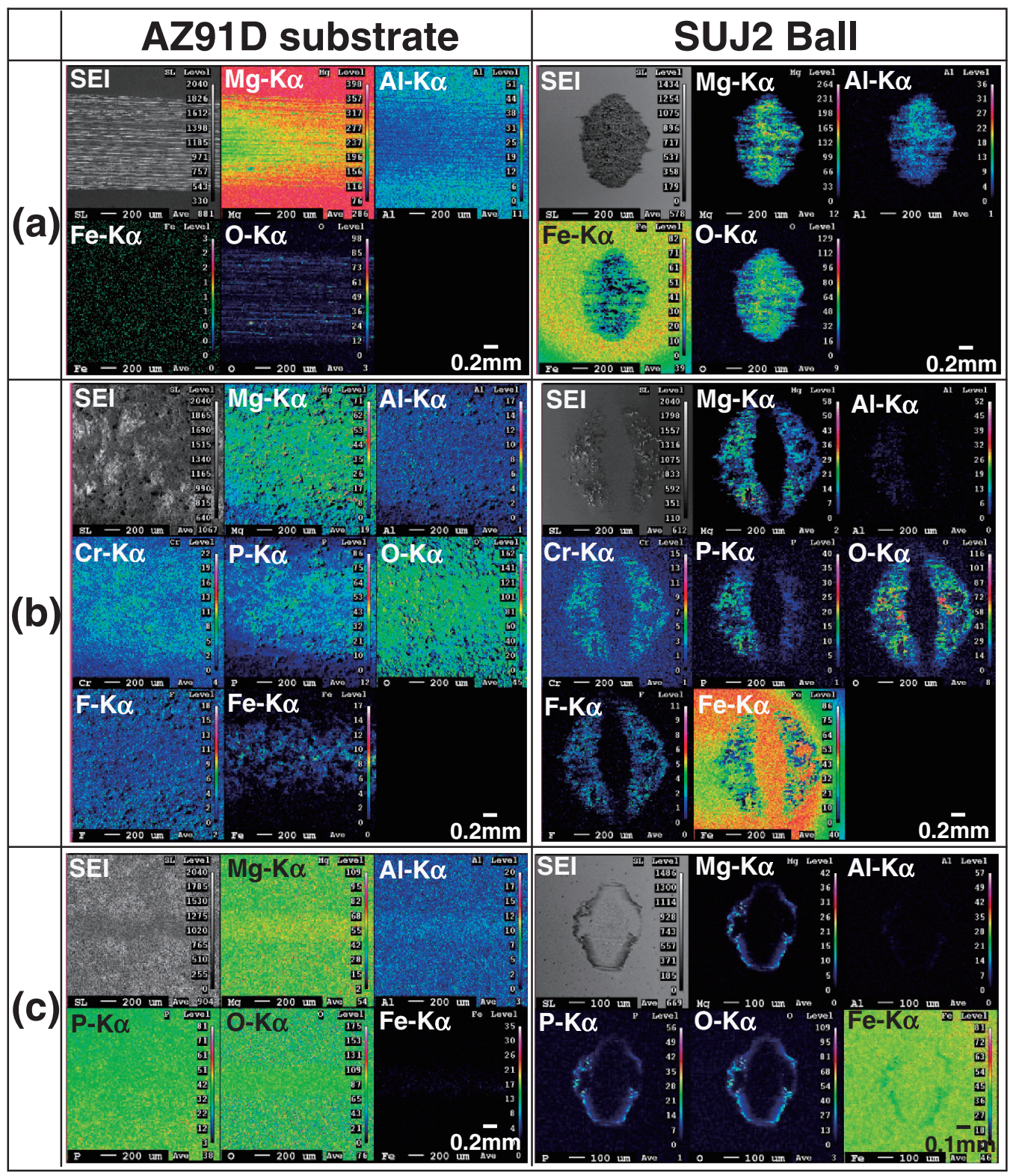

Fig. 6 Secondary electron images and X-ray maps obtained by FE-EPMA analysis for the various surface treated specimens after the friction and wear testing. (a) No treatment (b) Dow17 (c) Anodizing from the phosphate solution (Film thickness: $10 \mu \mathrm{m}$ ).

component, was distributed on the worn part of the SUJ2 ball. In addition, the elements derived from the coating were distributed on the worn edge shown in Fig. 6(b), so that the coating was significantly transferred to the SUJ2 ball. Since both the Dow17 coating and the SUJ2 ball wore each other as shown by these above results, the affinity of this combination between the Dow17 anodized coating and the SUJ2 ball seemed to be higher than that of the other combination.

On the other hand, on the anodized coating from the phosphate solution, not only the elements derived from the anodized coating, but also a few iron spots were distributed on the worn part of the coating. The iron, which was a main component, was distributed on the worn part of the SUJ2 ball. In addition, the elements derived from the coating were distributed on the worn edge shown in Fig. 6(c). However, the mutual transfer between the coating and SUJ2 ball is less than that of the combination between the Dow17 anodized coating and the SUJ2 ball. Consequently the mechanochemical affinity between the coating and the SUJ2 ball seems to have a significant effect on the wear resistance.

Finally, it was found that the anodizing from the phosphate solution on the magnesium alloy had excellent wear resistance against steel material such as SUS440C, except for the SUJ2 ball, shown in this study. However, a detailed wear mechanism is still unknown, so that a detailed examination is required to elucidate the exact wear mechanism.

\section{Conclusions}

The effects of the various surface treatments, such as anodizing from a phosphate solution, another anodizing by the Dow17 method, and conversion treatment on the friction 
and wear properties of the AZ91D magnesium alloy substrate were evaluated using a horizontal reciprocating friction and wear test under an oil-free condition. The following results were obtained.

(1) The anodized coating from a phosphate solution has excellent wear properties against the SUJ2 ball. This excellent property is attributed to the suppression of the mutual transfer between the coating and the SUJ2 ball.

(2) The conversion coating may have no influence on the friction and wear property. The hardness and thickness of the coating, and the hardness of the substrate seem to influence this wear property.

(3) The Dow17 anodized coating significantly wore, and the opposite SUJ2 ball also wore, so that this combination was not preferable for a sliding condition. It seems that the high affinity of both the coating and the SUJ2 ball promotes the abrasion, because a mutual transfer occurred at the wearing surface.

\section{REFERENCES}

1) Y. Kojima: J. Jpn. Inst. Light Met. 58 (2008) 526-548.

2) M. Hino, M. Hiramatsu, K. Murakami, A. Saijo and T. Kanadani: J. Jpn. Inst. Light Met. 56 (2006) 386-392.

3) The Dow Chemical Company, G.B. Pat.762,195 (1956).

4) H. A. Evangelides: U.S. Pat.2,723,952 (1955).

5) M. Hino, M. Hiramatsu, K. Murakami, A. Saijo and T. Kanadani: J. Surf. Finish. Soc. Jpn. 58 (2007) 767-771.

6) K. Murakami, M. Hino, M. Hiramatsu, A. Saijo, S. Kobayashi, K. Nakai and T. Kanadani: Mater. Trans. 48 (2007) 3101-3106.

7) K. Demizu, T. Sone, K. Adachi and Y. Yokoyama: J. Surf. Finish. Soc. Jpn. 48 (1997) 213-218.

8) M. Hino, M. Hiramatsu, M. Tsujikawa, M. Kawamoto and K. Demizu: J. Surf. Finish. Soc. Jpn. 51 (2000) 735-739.

9) M. Kuno, K. Demizu, I. Ishigami, K. Miura and E. Tsunasawa: J. Soc. Mater. Sci. Jpn. 42 (1993) 202-208.

10) M. Hino, M. Hiramatsu, K. Murakami and M. Tsujikawa: J. Jpn. Found. Eng. Soc. 80 (2008) 199-205.

11) Jpn. Soc. Tribologists (ed.): Tribology Dictionary, (Yokendo, 1995) (in Japanese) p. 259. 